\title{
Two New Types of Fixed Point Theorems in Complete Metric Spaces
}

\author{
Farshid Khojasteh,, ${ }^{1}$ Mujahid Abbas, ${ }^{2}$ and Simona Costache ${ }^{3}$ \\ ${ }^{1}$ Department of Mathematics, Arak Branch, Islamic Azad University, Arak, Iran \\ ${ }^{2}$ Department of Mathematics, Lahore University of Management Sciences, Lahore 54792, Pakistan \\ ${ }^{3}$ Department of Mathematics and Informatics, University Politehnica of Bucharest, 060042 Bucharest, Romania
}

Correspondence should be addressed to Simona Costache; simona_costache2003@yahoo.com

Received 12 May 2014; Accepted 13 June 2014; Published 26 June 2014

Academic Editor: Abdul Latif

Copyright (c) 2014 Farshid Khojasteh et al. This is an open access article distributed under the Creative Commons Attribution License, which permits unrestricted use, distribution, and reproduction in any medium, provided the original work is properly cited.

We introduce two new types of fixed point theorems in the collection of multivalued and single-valued mappings in complete metric spaces.

\section{Introduction}

Let $T$ be a mapping on a complete (or compact) metric space $(X, d)$. We do not assume richer structure such as convex metric spaces and Banach spaces. There are thousands of theorems which assure the existence of a fixed point of $T$. We can categorize these theorems into the following four types.

(T1) Leader type [1]: $T$ has a unique fixed point and $\left\{T^{n} x\right\}$ converges to the fixed point for all $x \in X$. Such a mapping is called a Picard operator in [2].

(T2) Unnamed type: $T$ has a unique fixed point and $\left\{T^{n} x\right\}$ does not necessarily converge to the fixed point.

(T3) Subrahmanyam type [3]: $T$ may have more than one fixed point and $\left\{T^{n} x\right\}$ converges to a fixed point for all $x \in X$. Such a mapping is called a weakly Picard operator in $[3,4]$.

(T4) Caristi type $[5,6]: T$ may have more than one fixed point and $\left\{T^{n} x\right\}$ does not necessarily converge to a fixed point.

We know that most of the theorems such as Banach's [7], Ćirić's [8], Kannan's [9], Kirk's [10], Matkowski’s [11], Meir and Keeler's [12], and Suzuki's [13, 14] belong to (T1). Also, very recently, Suzuki [15] characterized (T1). Subrahmanyam's theorem [3] belongs to (T3), and Caristi's theorem [5,6] and its generalizations [15-17] belong to (T4).
On the other hand, as far as the authors do know, there are no theorems belonging to (T2); see Kirk's survey [18]. Also, recently many interesting fixed point theorems are proved in the framework of ordered metric spaces; see [18-35] and others.

In this paper, motivated by the above, we introduce two new types of fixed point theorems in the collection of multivalued and single-valued mappings and will prove them, which belong to (T3).

Let $(X, d)$ be a metric space, and let $P_{\text {cl,bd }}(X)$ denote the class of all nonempty, closed, and bounded subsets of $X$. Let $T: X \rightarrow P_{\text {cl,bd }}(X)$ be a multivalued mapping on $X$. A point $x \in X$ is called a fixed point of $T$ if $x \in T x$. Set $\operatorname{Fix}(T)=\{x \in$ $X: x \in T x\}$.

A famous theorem on multivalued mappings is due to Nadler [36], which extended the Banach contraction principle to multivalued mappings. Many authors have studied the existence and uniqueness of strict fixed points for multivalued mappings in metric spaces; see, for example, [37-44] and references therein. that is,

Let $H$ be the Hausdorff metric on $P_{\mathrm{cl}, \mathrm{bd}}(X)$ induced by $d$;

$$
\begin{array}{r}
H(A, B):=\max \left\{\sup _{x \in B} d(x, A), \sup _{x \in A} d(x, B)\right\}, \\
A, B \in P_{\mathrm{cl}, \mathrm{bd}}(X) .
\end{array}
$$


Denote $\delta(x, A)=\sup \{d(x, y): y \in A\}$ and $D(x, A)=$ $\inf \{d(x, y): y \in A\}$, where $A \in P_{\mathrm{cl}, \mathrm{bd}}(X)$.

\section{Main Results}

The following is the first our main results.

Theorem 1. Let $(X, d)$ be a complete metric space and let $T$ be a mapping from $X$ into itself. Suppose that $T$ satisfies the following condition:

$$
d(T x, T y) \leq\left(\frac{d(x, T y)+d(y, T x)}{d(x, T x)+d(y, T y)+1}\right) d(x, y)
$$

for all $x, y \in X$. Then

(a) Thas at least one fixed point $\dot{x} \in X$;

(b) $\left\{T^{n} x\right\}$ converges to a fixed point, for all $x \in X$;

(c) if $\dot{x}, \dot{y}$ are two distinct fixed points of $T$, then $d(\dot{x}, \dot{y}) \geq$ $1 / 2$.

Proof. Let $x_{0} \in X$ be arbitrary and choose a sequence $\left\{x_{n}\right\}$ such that $x_{n+1}=T x_{n}$. We have

$$
\begin{aligned}
d\left(x_{n+1}, x_{n}\right) & =d\left(T x_{n}, T x_{n-1}\right) \\
& \leq\left(\frac{d\left(x_{n}, x_{n}\right)+d\left(x_{n-1}, x_{n+1}\right)}{d\left(x_{n}, x_{n+1}\right)+d\left(x_{n-1}, x_{n}\right)+1}\right) d\left(x_{n}, x_{n-1}\right) \\
& =\left(\frac{d\left(x_{n-1}, x_{n+1}\right)}{d\left(x_{n}, x_{n+1}\right)+d\left(x_{n-1}, x_{n}\right)+1}\right) d\left(x_{n}, x_{n-1}\right) \\
& \leq\left(\frac{d\left(x_{n-1}, x_{n}\right)+d\left(x_{n}, x_{n+1}\right)}{d\left(x_{n}, x_{n+1}\right)+d\left(x_{n-1}, x_{n}\right)+1}\right) d\left(x_{n}, x_{n-1}\right) .
\end{aligned}
$$

Given

$$
\beta_{n}=\frac{d\left(x_{n-1}, x_{n}\right)+d\left(x_{n}, x_{n+1}\right)}{d\left(x_{n}, x_{n+1}\right)+d\left(x_{n-1}, x_{n}\right)+1},
$$

we have

$$
\begin{aligned}
d\left(x_{n+1}, x_{n}\right) & \leq \beta_{n} d\left(x_{n}, x_{n-1}\right) \\
& \leq\left(\beta_{n} \beta_{n-1}\right) d\left(x_{n-1}, x_{n-2}\right) \\
& \vdots \\
& \leq\left(\beta_{n} \beta_{n-1} \cdots \beta_{1}\right) d\left(x_{1}, x_{0}\right) .
\end{aligned}
$$

Observe that $\left(\beta_{n}\right)$ is nonincreasing, with positive terms. So $\beta_{1} \cdots \beta_{n} \leq \beta_{1}^{n}$ and $\beta_{1}^{n} \rightarrow 0$. It follows that

$$
\lim _{n \rightarrow \infty}\left(\beta_{1} \beta_{2} \cdots \beta_{n}\right)=0
$$

Thus, it is verified that

$$
\lim _{n \rightarrow \infty} d\left(x_{n+1}, x_{n}\right)=0 .
$$

Now for all $m, n \in \mathbb{N}$ we have

$$
\begin{aligned}
d\left(x_{m}, x_{n}\right) \leq & d\left(x_{n}, x_{n+1}\right)+d\left(x_{n+1}, x_{n+2}\right) \\
& +\cdots+d\left(x_{m-1}, x_{m}\right) \\
\leq & {\left[\left(\beta_{n} \beta_{n-1} \cdots \beta_{1}\right)+\left(\beta_{n+1} \beta_{n} \cdots \beta_{1}\right)\right.} \\
& \left.+\cdots+\left(\beta_{m-1} \beta_{m-2} \cdots \beta_{1}\right)\right] d\left(x_{1}, x_{0}\right) \\
= & \sum_{k=n}^{m-1}\left(\beta_{k} \beta_{k-1} \cdots \beta_{1}\right) d\left(x_{1}, x_{0}\right) .
\end{aligned}
$$

Suppose that $a_{k}=\left(\beta_{k} \beta_{k-1} \cdots \beta_{1}\right)$. Since

$$
\lim _{k \rightarrow \infty} \frac{a_{k+1}}{a_{k}}=0
$$

$\sum_{k=1}^{\infty} a_{k}<\infty$. It means that

$$
\sum_{k=n}^{m-1}\left(\beta_{k} \beta_{k-1} \cdots \beta_{1}\right) \longrightarrow 0
$$

as $m, n \rightarrow \infty$. In other words, $\left\{x_{n}\right\}$ is a Cauchy sequence and so converges to $\dot{x} \in X$.

We claim that $\dot{x}$ is a fixed point.

Note that

$$
d\left(x_{n+1}, T \dot{x}\right) \leq\left(\frac{d\left(x_{n}, T \dot{x}\right)+d\left(\dot{x}, T x_{n}\right)}{d(\dot{x}, T \dot{x})+d\left(x_{n}, T x_{n}\right)+1}\right) d\left(x_{n}, \dot{x}\right) .
$$

On taking limit on both sides of (11), we have $d(\dot{x}, T \dot{x})=0$. Thus, $T \dot{x}=\dot{x}$.

If there exist two distinct fixed points $\dot{x}, \dot{y} \in X$, then

$$
\begin{aligned}
d(\dot{x}, \dot{y}) & =d(T \dot{x}, T \dot{y}) \\
& \leq[d(\dot{x}, T \dot{y})+d(T \dot{x}, \dot{y})] d(\dot{x}, \dot{y}) \\
& =2[d(\dot{x}, \dot{y})]^{2} .
\end{aligned}
$$

Therefore, $d(\dot{x}, \dot{y}) \geq 1 / 2$ and we find the desired results.

In the following, two examples of such type of mappings, which satisfy (2), are given.

Example 2. Let $X=\{0,1 / 2,1\}$ and let $d: X \times X \rightarrow[0, \infty)$ be defined by

$$
\begin{gathered}
d\left(0, \frac{1}{2}\right)=2, \quad d\left(1, \frac{1}{2}\right)=\frac{5}{2}, \quad d(0,1)=3, \\
d(0,0)=d\left(\frac{1}{2}, \frac{1}{2}\right)=d(1,1)=0, \\
d(a, b)=d(b, a), \quad \forall a, b \in X .
\end{gathered}
$$


$(X, d)$ is a complete metric space. Let $T: X \rightarrow X$ be defined by

$$
\begin{gathered}
T(0)=0, \quad T\left(\frac{1}{2}\right)=\frac{1}{2}, \quad T(1)=0 \\
d(T 0, T 1)=d(0,0)=0, \\
d\left(T 0, T\left(\frac{1}{2}\right)\right)=d\left(0, \frac{1}{2}\right)=2, \\
d\left(T 1, T\left(\frac{1}{2}\right)\right)=d\left(0, \frac{1}{2}\right)=2,
\end{gathered}
$$

and we have

$$
\begin{aligned}
d\left(T 0, T\left(\frac{1}{2}\right)\right)= & d\left(0, \frac{1}{2}\right)=2 \\
\leq & \left(\frac{d(0, T(1 / 2))+d(1 / 2, T(0))}{d(0, T 0)+d(1 / 2, T(1 / 2))+1}\right) \\
& \times d\left(0, \frac{1}{2}\right)=8
\end{aligned}
$$

and also

$$
\begin{aligned}
d\left(T 1, T\left(\frac{1}{2}\right)\right)= & d\left(0, \frac{1}{2}\right)=2 \\
\leq & \left(\frac{d(1, T(1 / 2))+d(1 / 2, T(1))}{d(1, T 1)+d(1 / 2, T(1 / 2))+1}\right) \\
& \times d\left(1, \frac{1}{2}\right) \\
= & \left(\frac{5 / 2+2}{4}\right) \times \frac{5}{2}=\frac{45}{16} .
\end{aligned}
$$

Therefore, $T$ satisfies all the conditions of Theorem 1 . Also, $T$ has two distinct fixed points $\{0,1 / 2\}$ and $d(0,1 / 2)=2 \geq 1 / 2$.

Example 3. Let $X=[0,2-\sqrt{3}]$ be endowed with Euclidean metric and let $T: X \rightarrow X$ be defined by

$$
T x= \begin{cases}0 & 0 \leq x<2-\sqrt{3} \\ 2-\sqrt{3} & x=2-\sqrt{3} .\end{cases}
$$

Then we claim that $T$ satisfies all the conditions of Theorem 1 .

If $x=2-\sqrt{3}$ and $0 \leq y<2-\sqrt{3}$, we have

$$
\begin{aligned}
\mid T x & -T y \mid(|x-T x|+|y-T y|+1) \\
& =(2-\sqrt{3})(|y|+1)=(2-\sqrt{3})(y+1) \\
& \leq(2-\sqrt{3}-y)^{2}-(2-\sqrt{3})(2-\sqrt{3}-y) \\
& =(|x-T y|+|y-T x|)|x-y| .
\end{aligned}
$$

Thus,

$$
|T x-T y| \leq\left(\frac{|x-T y|+|y-T x|}{|x-T x|+|y-T y|+1}\right)|x-y| .
$$

Similar argument holds for the other conditions.
Remark 4. Note that in (2) the ratio

$$
\frac{d(x, T y)+d(y, T x)}{d(x, T x)+d(y, T y)+1}
$$

might be greater or less than 1 and has not introduced an upper bound. Note that if, for every $x, y \in X, d(x, y)<1 / 2$, then we have

$$
\begin{aligned}
& d(x, T y)+d(y, T x) \\
& \quad \leq 2 d(x, y)+d(x, T x)+d(y, T y) \\
& \quad<d(x, T x)+d(y, T y)+1 .
\end{aligned}
$$

It means that

$$
\frac{d(x, T y)+d(y, T x)}{d(x, T x)+d(y, T y)+1}<1,
$$

and thus Theorem 1 is a special case of Banach contraction principle. Therefore, when $(X, d)$ is a complete metric space such that, for all $x, y \in X, d(x, y) \geq 1 / 2$, Theorem 1 is valuable because (20) might be greater than 1 . Example 2 shows this note precisely.

The following is the second in our main results.

Theorem 5. Let $(X, d)$ be a complete metric space and let $T$ be a multivalued mapping from $X$ into $P_{c l, b d}(X)$. Let $T$ satisfy the following:

$$
H(T x, T y) \leq\left(\frac{D(x, T y)+D(y, T x)}{\delta(x, T x)+\delta(y, T y)+1}\right) d(x, y),
$$

for all $x, y \in X$. Then $T$ has a fixed point $\dot{x} \in X$.

Proof. Let $x_{0} \in X$ and $x_{1} \in T x_{0}$. For each $0<h_{1}<1$ one can choose $x_{2} \in T x_{1}$ such that

$$
\begin{aligned}
d\left(x_{1}, x_{2}\right) & <H\left(T x_{0}, T x_{1}\right)+\left(1-\frac{1}{h_{1}}\right) H\left(T x_{0}, T x_{1}\right) \\
& =\frac{1}{h_{1}} H\left(T x_{0}, T x_{1}\right) .
\end{aligned}
$$

For each $0<h_{n}<1$ we can choose $x_{n+1} \in T x_{n}$ such that

$$
\begin{aligned}
d\left(x_{n}, x_{n+1}\right) & <H\left(T x_{n-1}, T x_{n}\right)+\left(1-\frac{1}{h_{n}}\right) H\left(T x_{0}, T x_{1}\right) \\
& =\frac{1}{h_{n}} H\left(T x_{0}, T x_{1}\right) .
\end{aligned}
$$

Specifically if

$$
\begin{aligned}
h_{n} & =\sqrt{\frac{d\left(x_{n-1}+x_{n+1}\right)}{d\left(x_{n-1}+x_{n}\right)+d\left(x_{n}+x_{n+1}\right)+1}} \\
& =\sqrt{\beta_{n}},
\end{aligned}
$$


then

$$
d\left(x_{n}, x_{n+1}\right) \leq \sqrt{\beta_{n}} d\left(x_{n-1}, x_{n}\right) \leq \beta_{n} d\left(x_{n-1}, x_{n}\right) .
$$

Therefore,

$$
\begin{aligned}
d\left(x_{n+1}, x_{n}\right) & \leq \beta_{n} d\left(x_{n}, x_{n-1}\right) \\
& \leq\left(\beta_{n} \beta_{n-1}\right) d\left(x_{n-1}, x_{n-2}\right) \\
& \vdots \\
& \leq\left(\beta_{n} \beta_{n-1} \cdots \beta_{1}\right) d\left(x_{1}, x_{0}\right) .
\end{aligned}
$$

It can easily be seen that

$$
\lim _{n \rightarrow \infty}\left(\beta_{1} \beta_{2} \cdots \beta_{n}\right)=0 .
$$

Thus, it is easily verified that

$$
\lim _{n \rightarrow \infty} d\left(x_{n+1}, x_{n}\right)=0 .
$$

Now for all $m, n \in \mathbb{N}$ we have

$$
\begin{aligned}
d\left(x_{m}, x_{n}\right) \leq & d\left(x_{n}, x_{n+1}\right)+d\left(x_{n}, x_{n+1}\right)+\cdots+d\left(x_{m-1}, x_{m}\right) \\
\leq & {\left[\left(\beta_{n} \beta_{n-1} \cdots \beta_{1}\right)+\left(\beta_{n+1} \beta_{n} \cdots \beta_{1}\right)\right.} \\
& \left.+\cdots+\left(\beta_{m-1} \beta_{m-2} \cdots \beta_{1}\right)\right] d\left(x_{1}, x_{0}\right) \\
= & \sum_{k=n}^{m-1}\left(\beta_{k} \beta_{k-1} \cdots \beta_{1}\right) d\left(x_{1}, x_{0}\right) .
\end{aligned}
$$

Suppose that $a_{k}=\left(\beta_{k} \beta_{k-1} \cdots \beta_{1}\right)$. Since

$$
\lim _{k \rightarrow \infty} \frac{a_{k+1}}{a_{k}}=0,
$$

$\sum_{k=1}^{\infty} a_{k}<\infty$. It means that

$$
\sum_{k=n}^{m-1}\left(\beta_{k} \beta_{k-1} \cdots \beta_{1}\right) \longrightarrow 0,
$$

as $m, n \rightarrow \infty$. In other words, $\left\{x_{n}\right\}$ is a Cauchy sequence and so converges to $\dot{x} \in X$. We claim that $\dot{x}$ is a fixed point. Consider

$$
\begin{aligned}
D(\dot{x}, T \dot{x}) \leq & d\left(\dot{x}, x_{n+1}\right)+D\left(x_{n+1}, T \dot{x}\right) \\
\leq & H\left(T x_{n}, T \dot{x}\right)+d\left(\dot{x}, x_{n+1}\right) \\
\leq & \left(\frac{D\left(\dot{x}, T x_{n}\right)+D\left(x_{n}, T \dot{x}\right)}{\delta(\dot{x}, T \dot{x})+\delta\left(x_{n}, T x_{n}\right)+1}\right) \\
& \times d\left(x_{n}, \dot{x}\right)+d\left(\dot{x}, x_{n+1}\right) \\
\leq & {\left[D\left(\dot{x}, x_{n+1}\right)+D\left(x_{n}, T \dot{x}\right)\right] } \\
& \times d\left(x_{n}, \dot{x}\right)+d\left(\dot{x}, x_{n+1}\right) .
\end{aligned}
$$

On taking limit on both sides of (31) we have $D(\dot{x}, T \dot{x})=0$. It means that $\dot{x} \in T \dot{x}$.

Remark 6. Note that Theorem 5 is a generalization of Theorem 1 because by taking $F x=\{T x\}$ and applying Theorem 5 for $F$ we obtain Theorem 1 .

\section{Conflict of Interests}

The authors declare that there is no conflict of interests regarding the publication of this paper.

\section{References}

[1] S. Leader, "Equivalent Cauchy sequences and contractive fixed points in metric spaces," Studia Mathematica, vol. 76, no. 1, pp. 63-67, 1983.

[2] I. A. Rus, "Picard operators and applications," Scientiae Mathematicae, vol. 58, no. 1, pp. 191-219, 2003.

[3] P. V. Subrahmanyam, "Remarks on some fixed point theorems related to Banach's contraction principle," Journal of Mathematical and Physical Sciences, vol. 8, pp. 445-457, 1974.

[4] I. A. Rus, A. S. Muresan, and V. Muresan, "Weakly Picard operators on a set with two metrics," Fixed Point Theory, vol. 6, no. 2, pp. 323-331, 2005.

[5] J. Caristi, "Fixed point theorems for mappings satisfying inwardness conditions," Transactions of the American Mathematical Society, vol. 215, pp. 241-251, 1976.

[6] J. Caristi and W. A. Kirk, "Geometric fixed point theory and inwardness conditions," in The Geometry of Metric and Linear Spaces, vol. 490 of Lecture Notes in Mathematics, pp. 74-83, Springer, Berlin, Germany, 1975.

[7] S. Banach, "Sur les operations dans les ensembles abstraits et leur application aux equations integrales," Fundamenta Mathematicae, vol. 3, pp. 133-181, 1922.

[8] L. B. Ćirić, "A generalization of Banach's contraction principle," Proceedings of the American Mathematical Society, vol. 45, pp. 267-273, 1974.

[9] R. Kannan, "Some results on fixed points-II," The American Mathematical Monthly, vol. 76, no. 4, pp. 405-408, 1969.

[10] W. A. Kirk, "Fixed points of asymptotic contractions," Journal of Mathematical Analysis and Applications, vol. 277, no. 2, pp. 645-650, 2003.

[11] J. Matkowski, "Integrable solutions of functional equations," Dissertationes Mathematicae, vol. 127, pp. 1-68, 1975.

[12] A. Meir and E. Keeler, "A theorem on contraction mappings," Journal of Mathematical Analysis and Applications, vol. 28, pp. 326-329, 1969.

[13] T. Suzuki, "Generalized distance and existence theorems in complete metric spaces," Journal of Mathematical Analysis and Applications, vol. 253, no. 2, pp. 440-458, 2001.

[14] T. Suzuki, "Several fixed point theorems concerning $\tau$-distance," Fixed Point Theory and Applications, vol. 2004, no. 3, pp. 195209, 2004.

[15] T. Suzuki, "A sufficient and necessary condition for the convergence of the sequence of successive approximations to a unique fixed point," Proceedings of the American Mathematical Society, vol. 136, no. 11, pp. 4089-4093, 2008.

[16] J. S. Bae, "Fixed point theorems for weakly contractive multivalued maps," Journal of Mathematical Analysis and Applications, vol. 284, no. 2, pp. 690-697, 2003.

[17] J. S. Bae, E. W. Cho, and S. H. Yeom, "A generalization of the Caristi-Kirk fixed point theorem and its applications to mapping theorems," Journal of the Korean Mathematical Society, vol. 31, no. 1, pp. 29-48, 1994.

[18] W. A. Kirk, "Contraction mappings and extensions," in Handbook of Metric Fixed Point Theory, W. A. Kirk and B. Sims, Eds., pp. 1-34, Kluwer Academic, Dordrecht, The Netherlands, 2001. 
[19] H. Aydi, W. Shatanawi, M. Postolache, Z. Mustafa, and N. Tahat, "Theorems for Boyd-Wong-type contractions in ordered metric spaces," Abstract and Applied Analysis, vol. 2012, Article ID 359054, 14 pages, 2012.

[20] S. Chandok and M. Postolache, "Fixed point theorem for weakly Chatterjea-type cyclic contractions," Fixed Point Theory and Applications, vol. 2013, no. 28, 2013.

[21] S. Chandok, Z. Mustafa, and M. Postolache, "Coupled common fixed point results for mixed $g$-monotone mapps in partially ordered G-metric spaces," University Politehnica of Bucharest Scientific Bulletin A, vol. 75, no. 4, pp. 13-26, 2013.

[22] Y. Chen, "Stability of positive fixed points of nonlinear operators," Positivity, vol. 6, no. 1, pp. 47-57, 2002.

[23] B. S. Choudhury, N. Metiya, and M. Postolache, "A generalized weak contraction principle with applications to coupled coincidence point problems," Fixed Point Theory and Applications, vol. 2013, article 152, 2013.

[24] R. H. Haghi, M. Postolache, and S. Rezapour, "On T-stability of the Picard iteration for generalized $\varphi$-contraction mappings," Abstract and Applied Analysis, vol. 2012, Article ID 658971, 7 pages, 2012.

[25] D. Ilić and V. Rakočević, "Common fixed points for maps on cone metric space," Journal of Mathematical Analysis and Applications, vol. 341, no. 2, pp. 876-882, 2008.

[26] J. Jachymski, "The contraction principle for mappings on a metric space with a graph," Proceedings of the American Mathematical Society, vol. 136, no. 4, pp. 1359-1373, 2008.

[27] V. Lakshmikantham and L. Ćirić, "Coupled fixed point theorems for nonlinear contractions in partially ordered metric spaces," Nonlinear Analysis: Theory, Methods \& Applications, vol. 70, no. 12, pp. 4341-4349, 2009.

[28] J. J. Nieto, R. L. Pouso, and R. Rodriguez-Lopez, "Fixed point theorems in ordered abstract spaces," Proceedings of the American Mathematical Society, vol. 135, no. 8, pp. 2505-2517, 2007.

[29] J. J. Nieto and R. Rodriguez-Lopez, "Contractive mapping theorems in partially ordered sets and applications to ordinary differential equations," Order, vol. 22, no. 3, pp. 223-239, 2005.

[30] J. J. Nieto and R. Rodríguez-López, "Existence and uniqueness of fixed point in partially ordered sets and applications to ordinary differential equations," Acta Mathematica Sinica, vol. 23, no. 12, pp. 2205-2212, 2007.

[31] D. O'Regan and A. Petruşel, "Fixed point theorems for generalized contractions in ordered metric spaces," Journal of Mathematical Analysis and Applications, vol. 341, no. 2, pp. 12411252, 2008.

[32] H. K. Pathak and N. Shahzad, "Fixed points for generalized contractions and applications to control theory," Nonlinear Analysis. Theory, Methods \& Applications, vol. 68, no. 8, pp. 21812193, 2008.

[33] W. Shatanawi and M. Postolache, "Common fixed point theorems for dominating and weak annihilator mappings in ordered metric spaces," Fixed Point Theory and Applications, vol. 2013, article 271, 2013.

[34] W. Shatanawi and M. Postolache, "Common fixed point results for mappings under nonlinear contraction of cyclic form in ordered metric spaces," Fixed Point Theory and Applications, vol. 2013, no. 60, 2013.

[35] Y. Wu, "New fixed point theorems and applications of mixed monotone operator," Journal of Mathematical Analysis and Applications, vol. 341, no. 2, pp. 883-893, 2008.
[36] J. Nadler, "Multi-valued contraction mappings," Pacific Journal of Mathematics, vol. 30, pp. 475-488, 1969.

[37] A. Amini-Harandi, "Endpoints of set-valued contractions in metric spaces," Nonlinear Analysis: Theory, Methods \& Applications, vol. 72, no. 1, pp. 132-134, 2010.

[38] A. Amini-Harandi, "Fixed point theory for set-valued quasicontraction maps in metric spaces," Applied Mathematics Letters, vol. 24, no. 11, pp. 1791-1794, 2011.

[39] L. B. Ciric and J. S. Ume, "Multi-valued non-self-mappings on convex metric spaces," Nonlinear Analysis: Theory, Methods \& Applications, vol. 60, no. 6, pp. 1053-1063, 2005.

[40] M. Fakhar, "Endpoints of set-valued asymptotic contractions in metric spaces," Applied Mathematics Letters, vol. 24, no. 4, pp. 428-431, 2011.

[41] N. Hussain, A. Amini-Harandi, and Y. J. Cho, "Approximate endpoints for set-valued contractions in metric spaces," Fixed Point Theory and Applications, vol. 2010, Article ID 614867, 13 pages, 2010.

[42] Z. Kadelburg and S. Radenović, "Some results on set-valued contractions in abstract metric spaces," Computers \& Mathematics with Applications, vol. 62, no. 1, pp. 342-350, 2011.

[43] S. Moradi and F. Khojasteh, "Endpoints of multi-valued generalized weak contraction mappings," Nonlinear Analysis: Theory, Methods \& Applications, vol. 74, no. 6, pp. 2170-2174, 2011.

[44] F. Khojasteh and Rakočević V., "Some new common fixed point results for generalized contractive multi-valued non-selfmappings," Applied Mathematics Letters, vol. 25, no. 3, pp. 287293, 2012. 


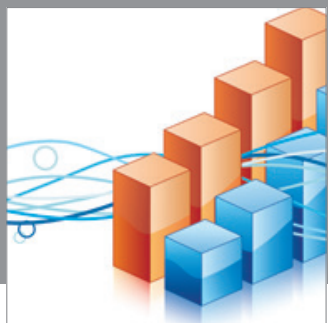

Advances in

Operations Research

mansans

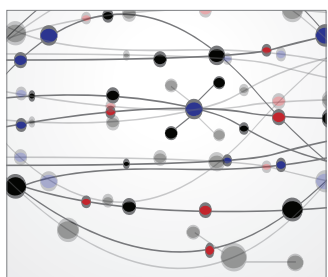

The Scientific World Journal
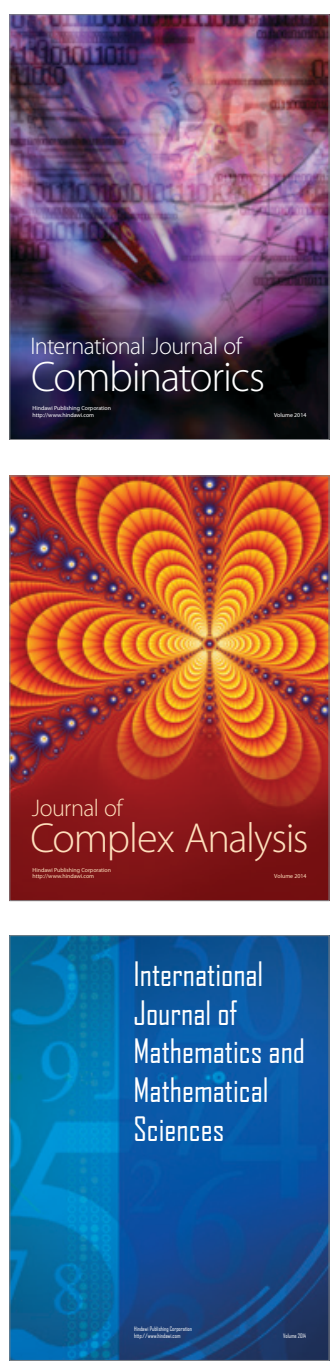
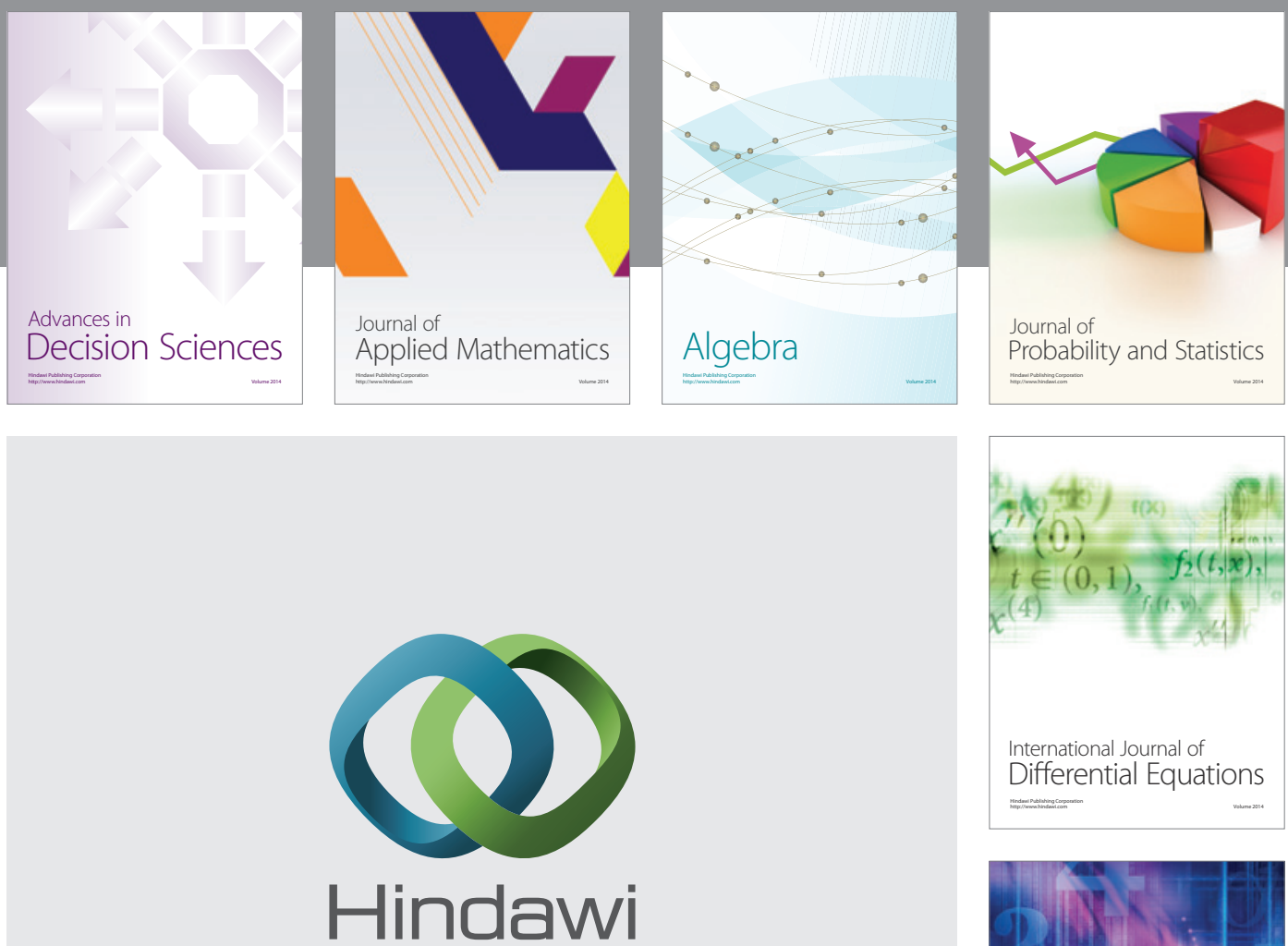

Submit your manuscripts at http://www.hindawi.com
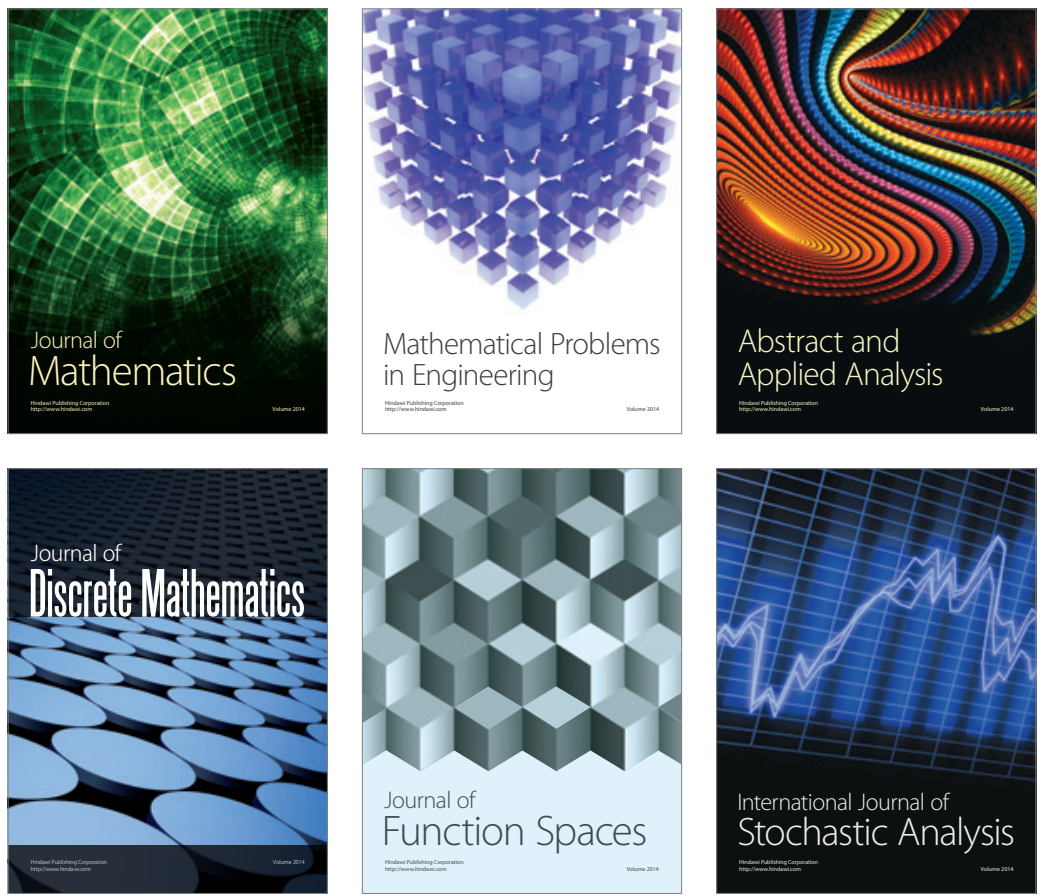

Journal of

Function Spaces

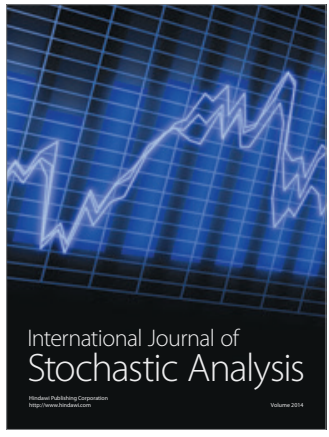

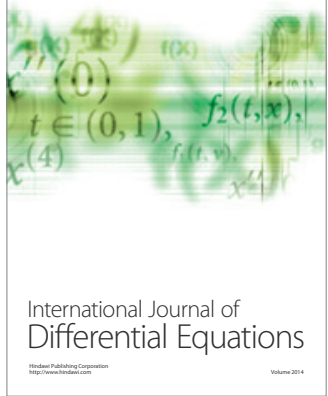
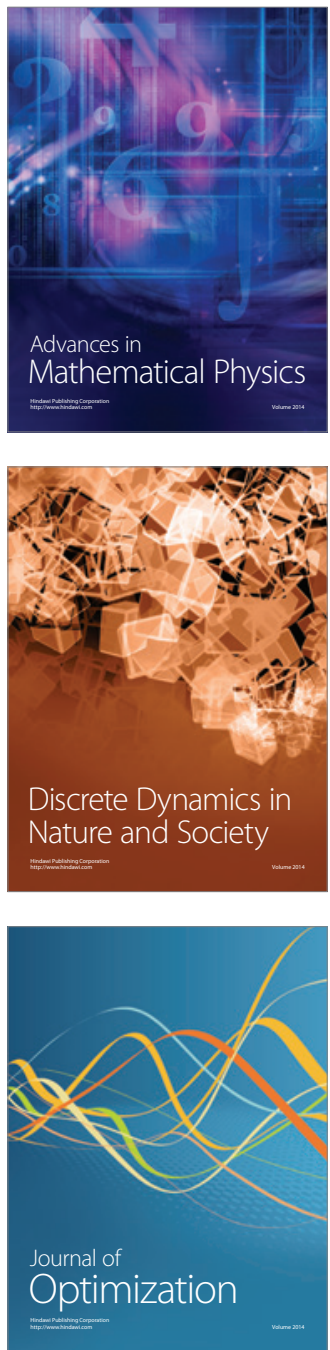